\title{
Rancang Bangun Sistem Informasi Penggajian Karyawan PT. Boetomix Nusantara Lestari Berbasis WEB
}

\author{
Rohmat Taufiq ${ }^{1}$, Rika Rahmawati ${ }^{2}$, Syepry Maulana Husain $^{3}$, Andhi Setiawan ${ }^{4}$ \\ 1,2,3 Teknik Informatika, University of Muhammadiyah Tangerang, Jalan Perintis Kemerdekaan I \\ Babakan No.33, RT.007/RW.003, Cikokol, Kec. Tangerang, Kota Tangerang, Banten 15118 \\ ${ }^{4}$ Teknik Informatika, Sekolah Tinggi Teknologi Muhammadiyah AR- Fachruddin Bojonegoro, \\ Sumberrejo Bojonegoro 62191 \\ e-mail: 1'rohmat.taufiq@umt.ac.id; ${ }^{2}$ rikarahmawati525@gmail.com; ${ }^{3}$ syepry.maulana@umt.ac.id; \\ ${ }^{4}$ andhisetiawan@sttmarfachruddin.ac.id;
}

Submitted Date: March 09 ${ }^{\text {th }}, 2021$

Revised Date: June $13^{\text {th }}, 2021$
Reviewed Date: May $31^{\text {st }}, 2021$

Accepted Date: June $15^{\text {th }}, 2021$

\begin{abstract}
Design of payroll information systems and requests for funds to the company PT. Boetomix Nusantara Lestari WEB-based still uses Microsoft Excel. By using MS Excel, errors that occur in inputting data and requesting payroll data have many errors. The process of sending goods data still uses whatsapp, because whatsapp used by the salary recapitulation officer has difficulty at the end of every month. This application designed has the aim of providing convenience for users so that the recitation process at PT. Boetomix Nusanara Lestari can run quickly and has a high level of accuracy. Interviews, observations and document analysis are methods used in the data collection process. Unified Modeling Language (UML) is used to describe running business processes and the relationship between users and the system. The employee payroll information system has been tested and the results are in accordance with the needs of PT. Boetomix Nusanara Lestari.
\end{abstract}

Keywords: Design, Application, Payroll, Employees, Unified Modeling Language.

\section{Abstrak}

Rancang bangun sistem informasi penggajian dan permintaan dana ke perusahaan PT. Boetomix Nusantara Lestari Berbasis WEB masih menggunakan Microsoft Excel. Dengan menggunakan ms excel maka kesalahan yang terjadi dalam melakukan input data dan pemrosesan data penggajian banyak terjadi kesalahan. Proses pengiriman data barang masih menggunakan whatsapp, karena whatsapp yang digunakan maka petugas bagian rekap gaji mengalami kesulitan di setiap akhir bulan. Aplikasi yang dirancang ini memiliki tujuan untuk memberikan kemudahan bagi pengguna sehingga proses penggajian di PT. Boetomix Nusanara Lestari bisa berjalan secara cepat dan memiliki tingkat akurasi yang tinggi. Wawancara, observasi dan menganalisis dokumen merupakan metode yang dilakukan dalam proses mengumpulkan data. Unified Modeling Language (UML) digunakan untuk menggambarkan proses bisnis yang berjalan dan hubungan antara pengguna dengan sistem. Sistem informasi penggajian karyawan sudah dilakukan uji coba dan hasilnya sesuai dengan kebutuhan PT. Boetomix Nusanara Lestari.

Kata Kunci: Perancangan, Aplikasi, Penggajian, Karyawan, Unified Modeling Language.

\section{Pendahuluan}

Salah satu sumber daya yang ada dalam perusahaan adalah pegawai. Kontribusi pegawai dalam perusahaan menjadikan salah satu komponen penting untuk berkembangnya sebuah perusahaan. Pegawai mendapatkan imbalan atau upah atau gaji sesuai dengan yang sudah disepakati, ada yang harian, mingguan maupun bulanan. Pada umumnya gaji seorang pegawai diberikan dalam bentuk uang sebagai timbal balik usaha atau jasa yang sudah dilakukan. Dengan kompleksnya pekerjaan dan jumlah pegawai yang banyak maka proses dalam menghitung gaji dan proses 
pemberian juga harus dipikirkan matang-matang oleh perusahaan.

PT. Betomix Nusantara Lestari merupakan perusahaan yang model perhitungan penggajian masih meggunakan sistem semi komputer. PT. Betomix Nusantara Lestari yang berdiri pada awal tahun 2014 yang lokasi kantor pusatnya berada di Tangerang Selatan dan Workshop atau Pabriknya yang beralamatkan di Komplek ALP 88 CurugTangerang. Salah satu perusahaan yang berkembang dengan pesat dalam penjualan Beton Mix instan. Untuk melakukan proses pengolahan data gaji karyawan PT. Betomix Nusantara Lestari masih menggunakan Semi Komputerisasi yaitu berdasarkan jumlah dan mutu produksi.

Dengan pesatnya teknologi di era berbasis web seperti sekarang ini maka secara otomatis sistem informasi menjadi sangat penting untuk meningkatkan kekuatan dalam bersaing. Dengan sistem informasi berbasis web maka diharapkan proses input data semakin mudah, pemrosesan data semakin cepat dan akurat serta pemberian informasi bisa sangat cepat. Sistem informasi berbasis web sangat diutamakan dalam memproses kegiatan yang ada di perusahaan khususnya bidang penggajian karyawan.

Sistem penggajian yang masih menggunakan Semi komputerisasi dengan mengirimkan melalui whatsapp maka akan membutuhkan waktu yang lamad dan dinilai kurang efisien.

Berdasasrkan latar belakang diatas maka penulis mengusulkan sebuah sistem informasi penggajian berbasis web agar memberikan kemudahan bagi semua pihak yang ada di PT. Betomix Nusantara Lestari.

\section{Landasan Teori}

\subsection{Rancang Bangung}

Suatu kegiatan yang menjelaskan dalam bentuk gambar secara rinci dari sistem yang sedang berjalan disebut dengan perancangan sistem (Satzinger, Jakson dan Burd, 2012). Laporan akhir dari hasil analisis sistem yang selanjutnya dilakukan pengembangan dalam bentuk spesifikasi baru itulah yang disebut dengan perancangan (Subhan, 2012). Menurut Munawar dalam Syepry dkk menjelaskan bahwa perancangan adalah pembangunan sebuah sistem walaupun adakalanya tidak di implementasikan (Syepry dkk, 2020). Analisis sistem dilakukan di awal sebelum langkah perancangan sistem dilakukan (Pertiwi dan Taufiq, 2020). Hasil dari analisis selanjutnya dilakukan perancangan berbasis web (Taufiq dkk, 2020).
Langkah-langkah yang dilakukan dalam perancangan sistem dimulai dari tapah analisis yang selanjutnya dilakukkan tahap desain sehingga perancangan bisa dilakukan secara benar (Mahdiana, 2011). Sedangkan akhir dari perancangan agar kebutuhan user terpenuhi sehingga implementasi yang dibuat bisa dimanfaatkan dengan baik oleh pengguna (Darmawan, 2013).

\subsection{Sistem Informasi}

Untuk mencapai satu tujuan tertentu maka kumpulan sub sub sistem saling berhubungan dan bekerja sama, itu merupakan definisi dari sebuah sistem (Taufiq dkk, 2020). Jika dilihat dari sisi definisi sistem dan prosedur tidaklah sama walaupun secara umum ada diantara kita yang menyebutnya bahwa sistem adalah prosedu dan prosedur adalah sistem. Sistem merupakan keterpaduan dari jaringan prosedur yang berfungsi melaksanakan kegiatan inti dari perusahaan sedangkan prosedur merupakan aktivitas klerikal yang secara umumnya melibatkan beberapa orang dalam suatu bagian agar kegiatan yang sifatnya berulang-ulang bisa dilakukan (Mulyadi, 2014). Sedangkan menurut penulis yang lain menjelaskan bahwa sistem informasi merupakan proses pengolahan data sehingga memiliki nilai lebih dan memiliki kegunaan bagi pengguna dengan cara mengintegrasikan sub-sub sistem (Taufiq, 2018).

\subsection{Penggajian}

Mardi (2011) menjelaskan bahwa "Gaji adalah hak yang diberikan kepada karyawan oleh perusahaan sebagai penghargaan kepada karyawan". Pada umumnya gaji diberikan kepada level manager sebulan sekali berupa uang (Mulyadi, 2016). Dengan kinerja yang baik bagi para pegawai dan peningkatan hasil kerja yang terus bertambah, maka hal tersebut lah yang diharapkan oleh perusahaan (Hasibuan, 2002).

\subsection{Karyawan}

Setiap orang yang melakukan pekerjaan agar output berupa barang dan jasa agar kebutuhannya atau kebutuhan masyarakat secara umum bisa di penuhi (UU No. 13, 2003).

\section{Metode Penelitian}

Dalam penelitian ini yang dilakukan menggunakan 2 tahap yaitu metode pencarian data dan metode perancangan sistem. Dalam pencarian data yang dilakukan yaitu dengan cara wawancara 
dengan semua pihak yang terlibat, observasi dilapangan dan studi literature dari berbagai sumber yang ada hubungannya dengan penelitian ini.

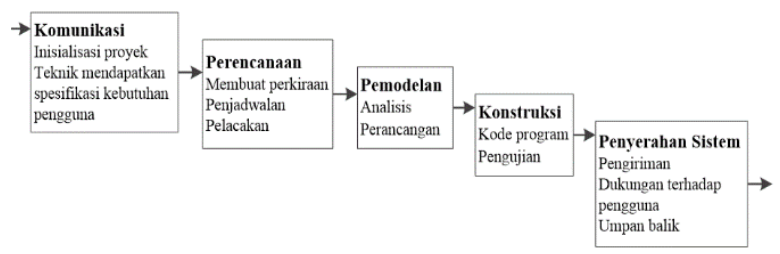

Gambar 1. Metode Pengembangan Sistem

Sedangkan metode perancangan sistem yaitu dengan metode waterfall, dalam metode waterfall ini akan menggambarkan sebuah pendekatan yang sistematis yang dimulai dari komunikasi yang selanjutnya dilakukan sebuah pembuatan rencana yang baik, proses pembuatan model serta pembuatan program aplikasi yang yang terakhir adalah pengantaran sistem dan perawatan secara bertahap agar sistem bisa berjaan degan baik.

\section{Analisis dan Perancangan}

4.1 Analisis sistem yang berjalan

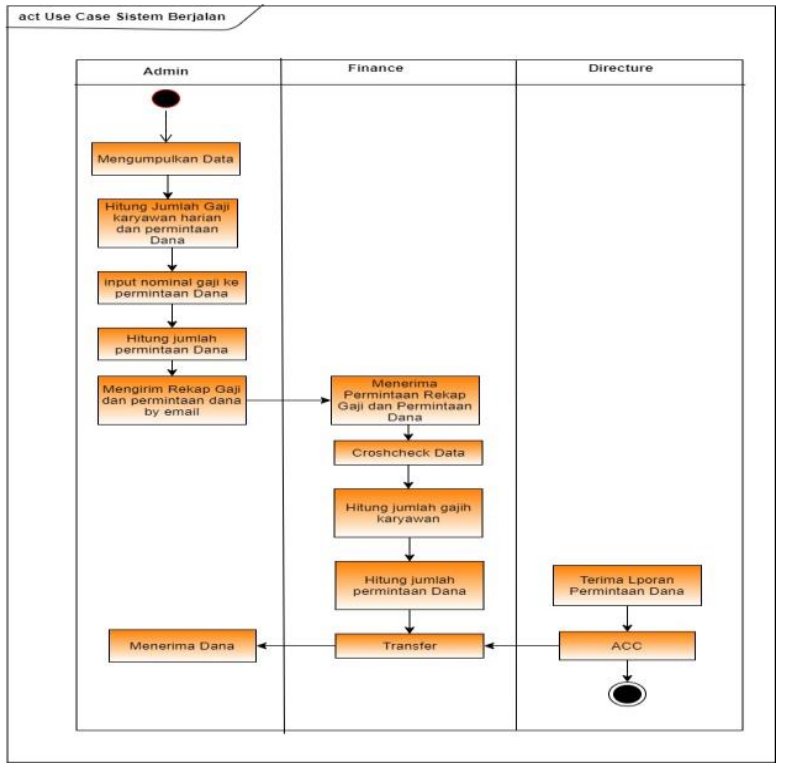

Gambar 2. Sistem berjalan

Setelah melakukan wawancara dengan pihak yang terlibat dan melihat langsung di lapangan atau tempat penelitian di PT. Betomix Nusantara Lestari, penggajian karyawan borongan, dapat disimpulkan bahwa sistem yang berjalan sampai sekarang proses untuk mengolah data serta untuk mengecek data penggajian dilakukan secara manual yang belum menggunakan sistem informasi berbasis web. Beberapa masalah yang ada dengan menggunakan sistem manual diantaranya: penyimpanan data yang kurang akurat dan data menggunakan aplikasi Microsoft Excel.

\subsection{Desain}

Pembuatan use case diagram

Use Case Diagram Aplikasi Sitem Penggajian Pt. Betomix Nusantara Lestari berbasis Web.

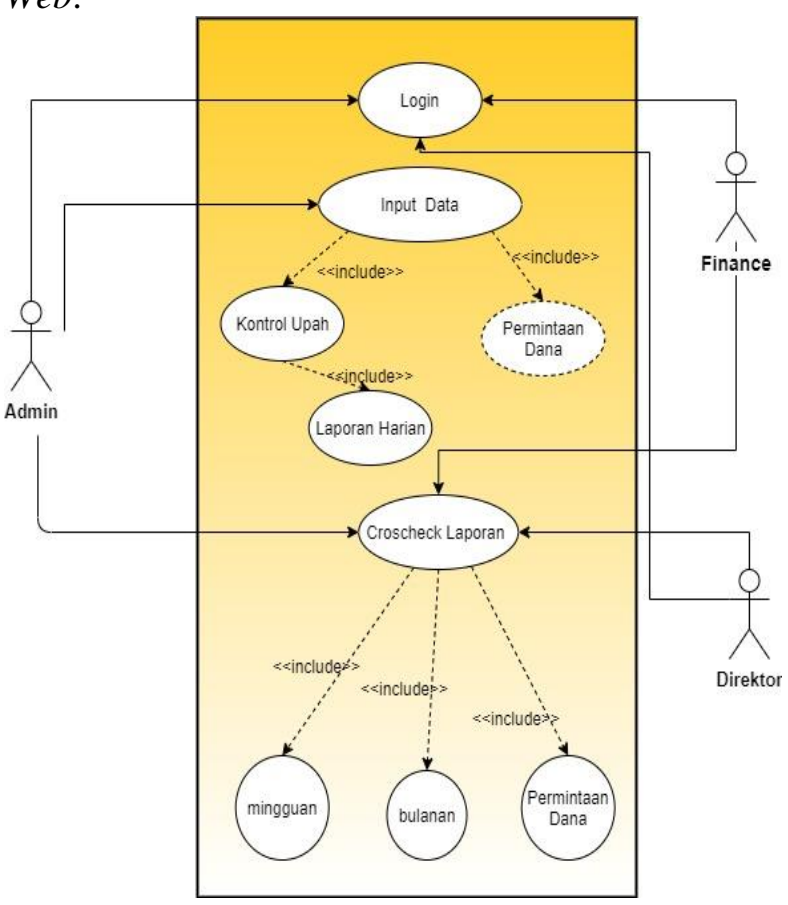

Gambar 3. Use Case

Ada 3 orang pengguna dalam use case tersebut yang terdiri dari admin, finance dan direktur. Masing-masing aktor diberikan hak akses yang berbeda-beda sehingga sistem akan berjalan secara baik tidak adanya tumpeng tindih.

\section{Activity diagram}

Dalam penggambaran activity diagram ini terdapat beberapa kegiaatan diantaranya activity diagram login, input data harian, data customer, permintaan dana, laporan mingguan, laporan bulanan, laporan permintaan dana, finance, croshcheck laporan permintaan. Dari semua activity hanya 1 activity yang ditampilkan di paper ini yaitu activity laporan bulanan. 


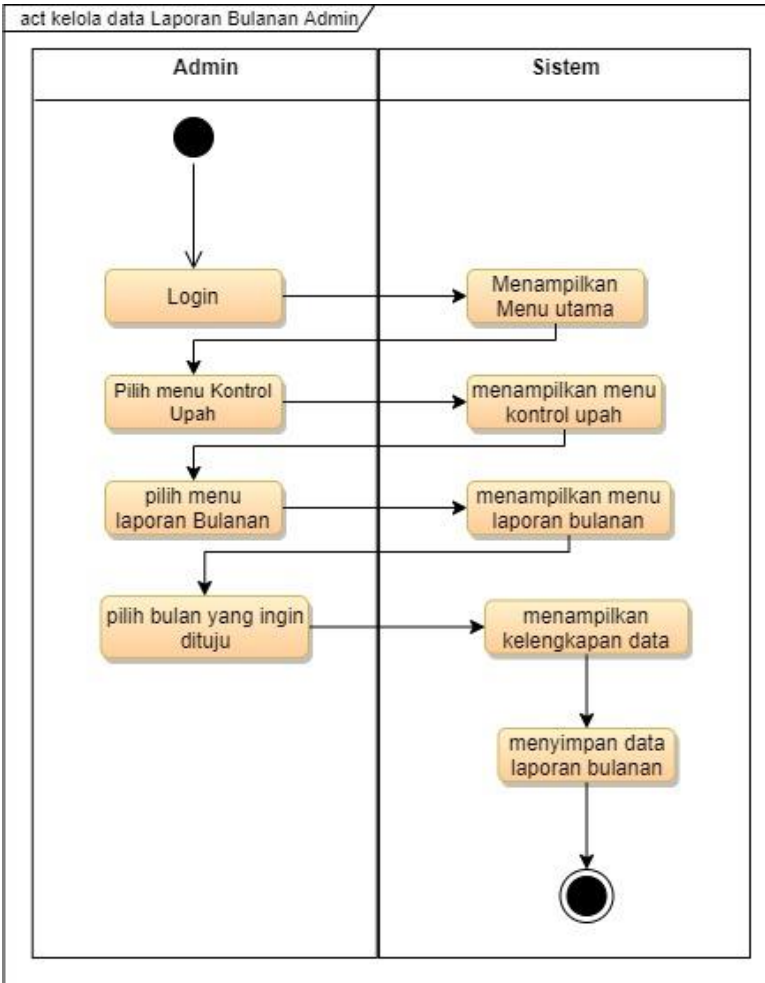

Gambar 4. Activity laporan bulanan

Dalam gambar 4 tentang laporan bulanan yang dibuat oleh admin. Admin melakukan login terlebih dahulu setelah itu masuk ke menu utama selanjutnya pilih menu control upah sampai dengan langkah yang terakhir yaitu menyimpan data laporan bulanan.

\section{Statechart Diagram laporan Bulanan}

Statechart diagram laporan bulanan dimulai dari masuk ke menu utama lalu menu control upah selanjutnya pilih bulan yang dituju. Langkah selanjutnya dilakukan sampai data bisa disimpan.

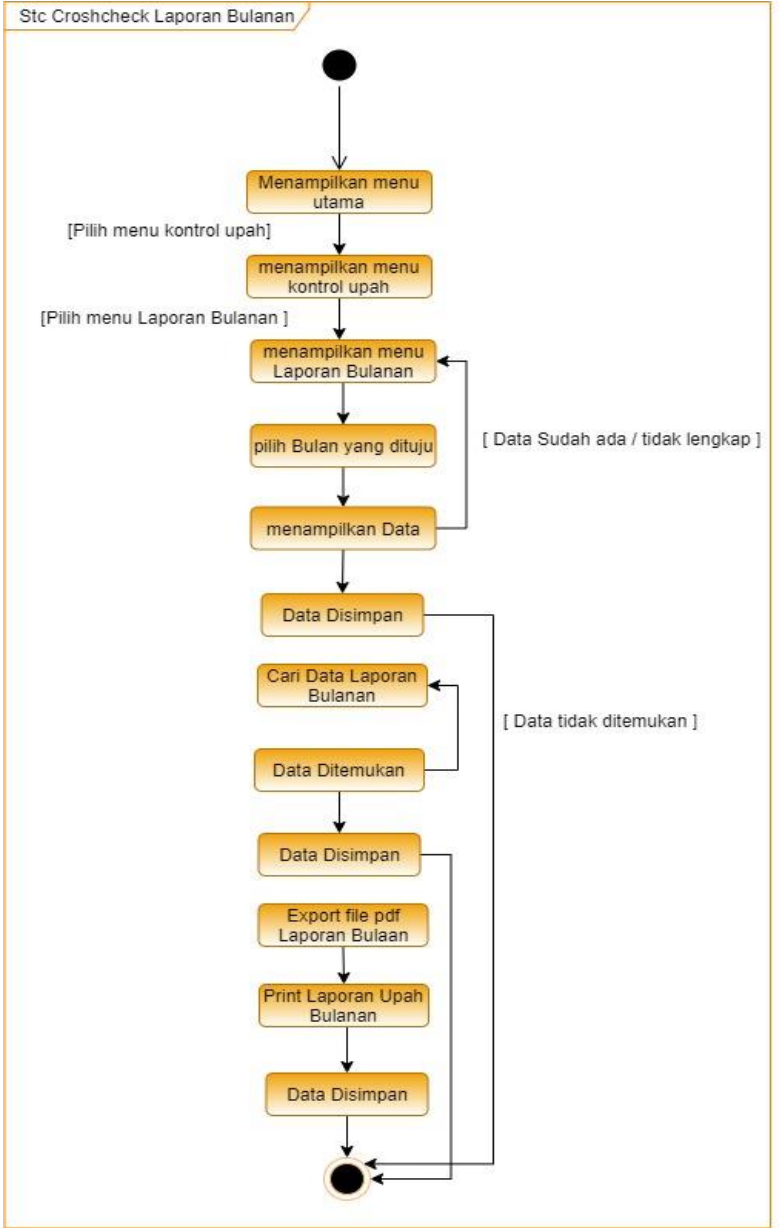

Gambar 5 Statechart Diagram Laporan Bulanan

Sequence Diagram Laporan Bulanan

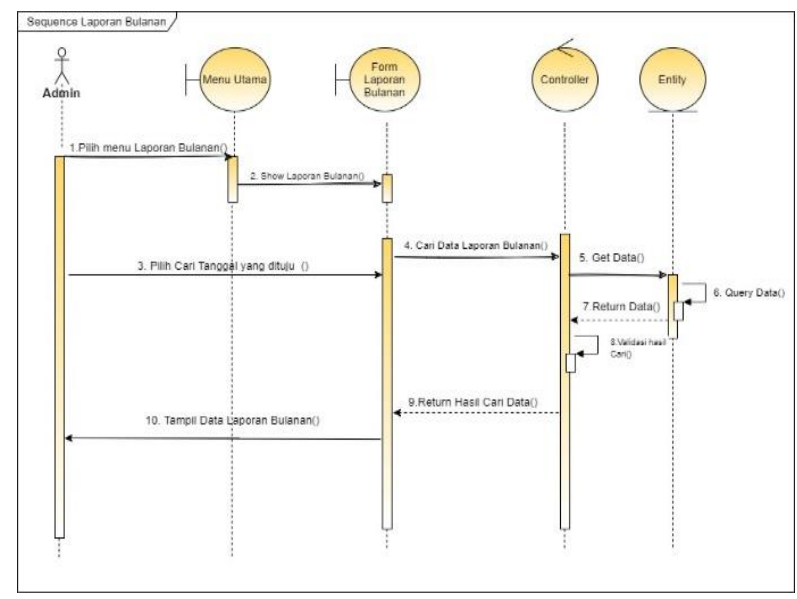

Gambar 6. Squence Diagram Laporan Bulanan

Gambar 6 diatas menjelaskan bagaimana seorang aktor berhubungan dengan sistem. Salah satu aktor yang ada dalam sequence diagram ini yaitu admin, dimana admin bisa membuat laporan bulanan, dimana laporan ini terdiri dari penjumlahan akumulasi dari laporan harian atau laporan mingguan. 
Desain Menu Utama

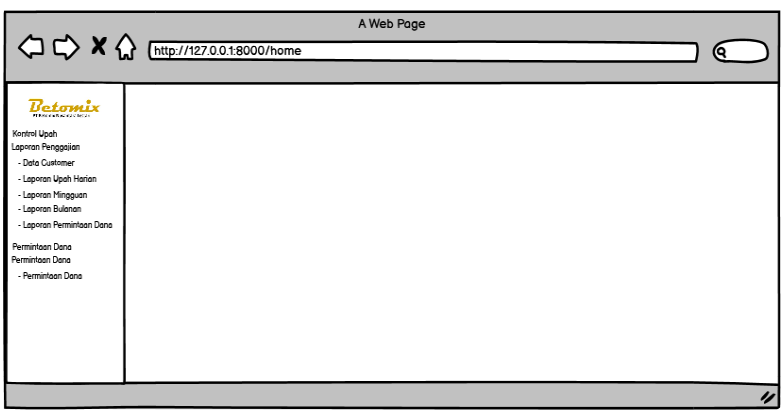

Gambar 7 Desain Menu Utama

Desain Menu Utama diatas digunakan untuk mempermudah seorang programmer dalam membuat aplikasi. Menu utama terdiri dari kontrol upah, laporan penggajian yang include didalamnya data customer dan lain-lain. Selain itu juga berisi form untuk meminta dana.

Desain Data Customer

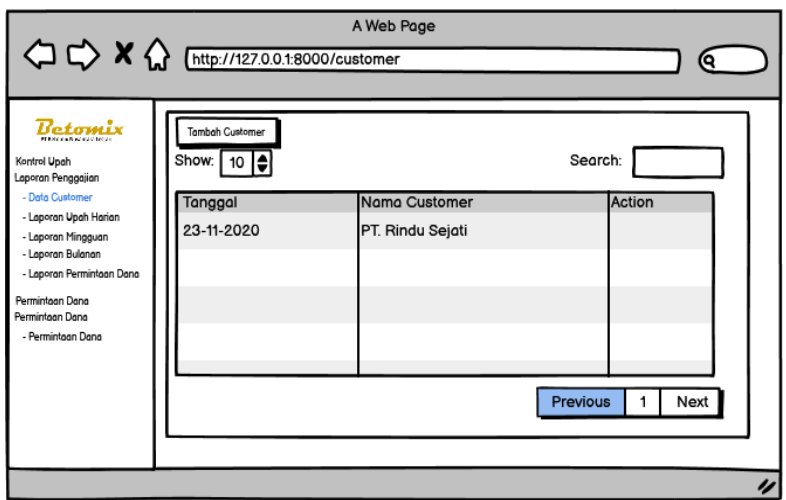

Gambar 8 Desain Data Customer

Desain data customer diatas menggambarkan bagaimana seorang admin yang nantinya bisa menggunakan aplikasi tersebut. desain ini dibuat sesuai dengan kebutuhan dan keadaan di perusashaan tersebut.

Desain Laporan Bulanan

Laporan bulanan yang tertera dalam desain ini berfungsi untuk admin bagian keuangan menyerahkan laporan bulanan kepada bagian fianance dan direktur.

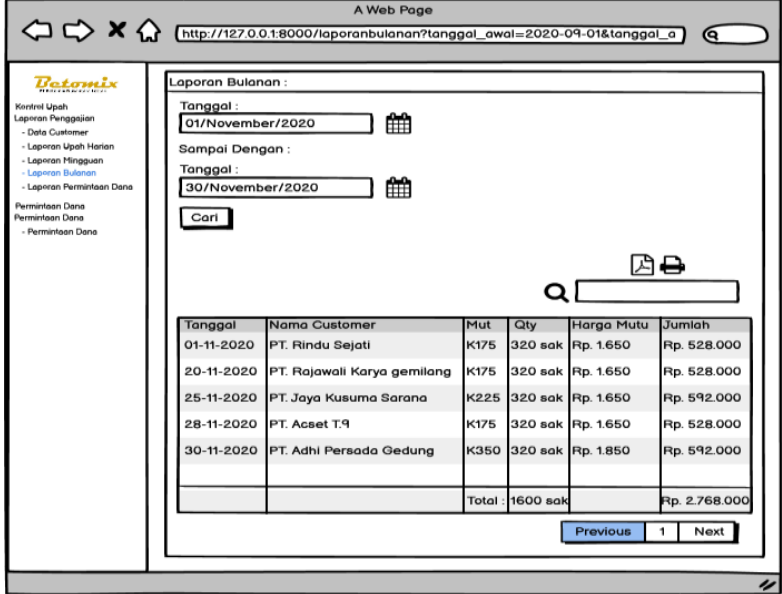

Gambar 9 Desain Laporan Bulanan

4.3 Implementasi

Form login

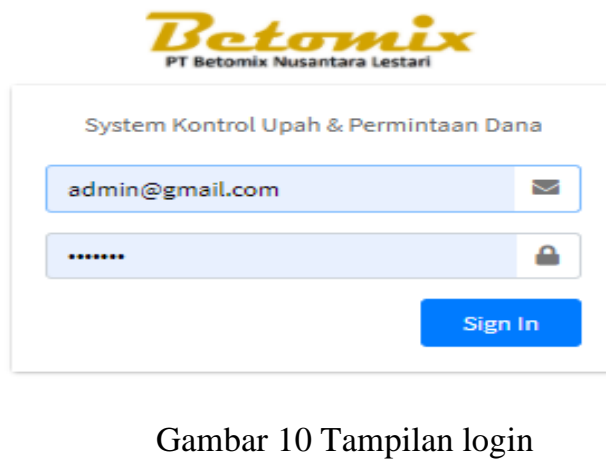

Gambar 10 diatas menjelaskan tampilan login yang akan digunakan oleh user untuk masuk ke sistem. Terdapat 3 orang user yang diberikan hak akses untuk login tersebut yang terdiri dari admin, finance dan satu orang direktur. Masing-masing aktor memiliki password yang berbeda-beda dan hak akses yang berbeda-beda juga.

\section{Form Menu Utama}

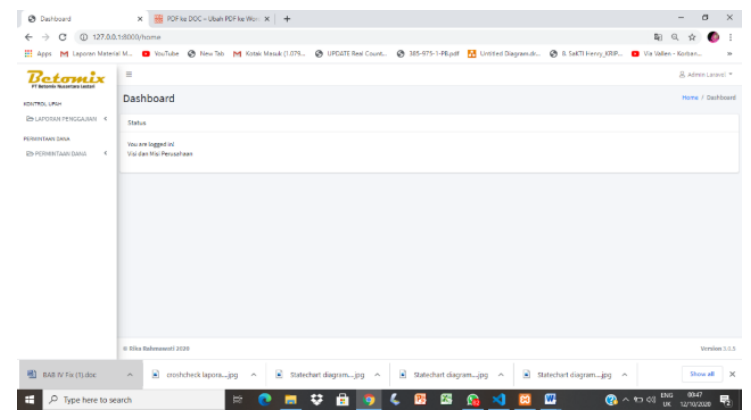

Gambar 11. Form Menu Utama

Gambar 11 diatas menjelaskan bagaiman seorang aktor atau user bisa mengunakan aplikasi ini setelah masuk login. Form menu utama ini bisa 
berfungsi untuk membuat laporan penggajuan melalui control upah dan bisa juga digunakan untuk permohonan data melalui permintaan dana.

\section{Form Data Customer}

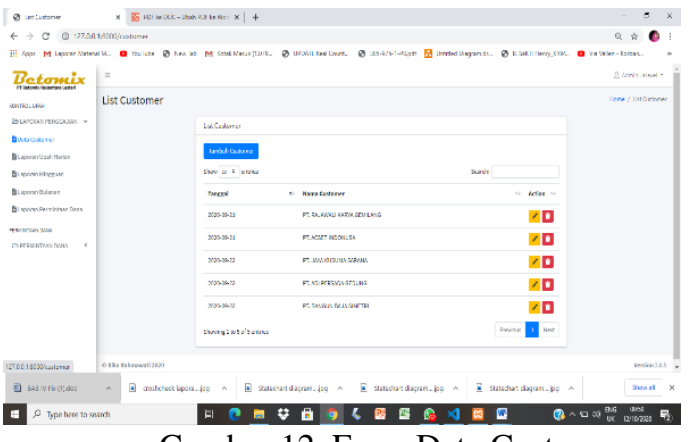

Gambar 12. Form Data Customer

Form data customer berisi data-data dari customer yang ada. Form ini berisi tentang tanggal transaksi dan nama customer. Form ini dibuat untuk memudahkan bagi perusahaan dalam mengingat identitas customer yang sudah ada. Dalam form ini bisa digunakan untuk edit data dan hapus data customer jika admin melakukan kesalahan dalam input data.

\section{Form Laporan Bulanan}

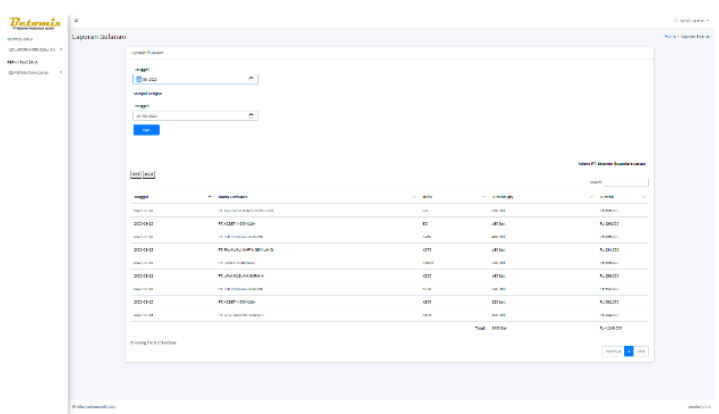

Gambar 13. Form Laporan Bulanan

Form laporan bulanan seperti yang tertera pada gambar 13 diatas menjelaskan bagaimana seorang admin membuat laporan bulanan. Dalam laporan ini yang terjadi sebenarnya ada laporan harian, laporan mingguan dan laporan bulanan.

Dalam laporan bulan ini menjadi sangat penting karena laporan inilah yang digunakan oleh direktur untuk melakukan Analisa. Form ini terdiri dari input tanggal, bulan dan tahun sehingga akan muncul identitas dari customer di waktu tersebut.

Form Laporan Permintaan Dana

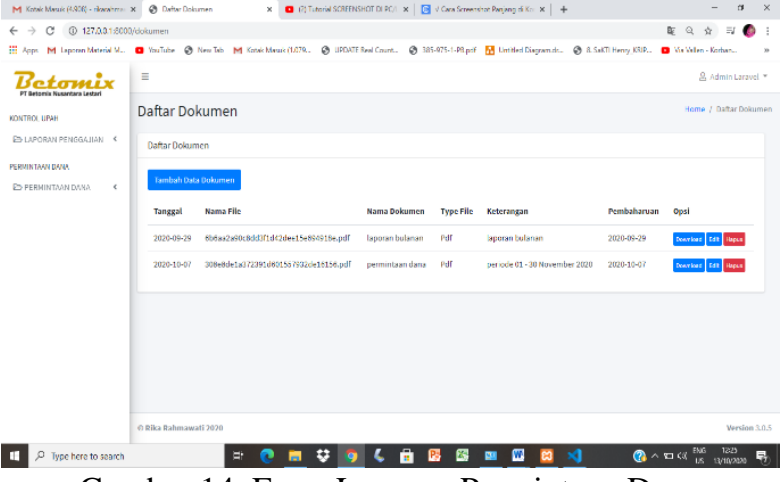

Gambar 14. Form Laporan Permintaan Dana

Form laporan permintaan dana tersebut digunakan oleh admin untuk mengajuan dana yang dibutuhkan. Dalam form tersebut berfungsi untuk memaukan keterangan yang sudah di isi point per point di dalamnya dan yang kedua adalah nominal keuangan yang dibutuhkan.

\section{Kesimpulan}

Dari pembahasan mengenai sistem pengolahan data penggajian karyawan PT. Betomix Nusantara Lestari, maka penulis menyimpulkan dari seluruh pokok bahasan yaitu sebagai berikut:

1. Dengan perancangan sistem informasi penggajian karyawan pada PT. Betomix Nusantara Lestari memiliki beberapa keuntungan yaitu sebagai berikut:

a. Dapat meminimalisir kesalahan yang bersifat human error.

b. Pengolahan data akan menghasilkan laporan yang akurat, tepat waktu dan relevan.

c. Pencarian data dan penyimpanan data lebih mudah dan cepat.

d. Peningkatan efisiensi dan efektifitas kinerja karyawan.

2. Hasil dari evaluasi dari sistem ini adalah sistem yang dapat berjalan dengan cukup baik dan admin dapat menggunakan sistem ini dengan cukup baik, sehingga sistem penggajian berbasis web ini dapat diterpkan pada perusahaan PT. Betomix Nusantara Lestari.

\section{Referensi}

Darmawan. 2013. Metode Penelitian Kuantitatif. Bandung: Remaja Rosdakarya

Hasibuan, Malayu SP (2002). Manajemen Sumber Daya Manusia. PT. Bumi Perkasa. Jakarta.

Husain, SM. Azhari, L. Taufiq, R dan Rahma, A (2020). Rancang Bangun Aplikasi E-Library Fakultas Teknik Universitas Muhammadiyah Tangerang. Jurnal Informatika UMT. E ISSN: 2722-2713. November 2020. Pp. 64-72. 
Mahdiana, D (2011). Analisa dan Rancangan Sistem Informasi Pengadaan Barang Dengan metodologi Berorientasi Objek: Studi Kasus PT. Liga Indonesia. Jurnal Telematika mkom, Vol. 3 No. 2. September 2011.

Mardi (2011). Sistem Informasi Akuntansi. Ghalia Indonesia. Jakarta.

Mulyadi (2016). Sistem Informasi Akuntansi. Salemba Empat. Jakarta.

Pertiwi, D.D and Taufiq, R. 2020. “Analisis dan Desain Sistem Informasi Pengolahan Nilai Siswa di SMK Avicena Rajeg”, J. Tek. Inform. Univ. Muhammadiyah Tangerang. ISSN: 2549-0710.

Satzinger, JW., Jackson, RB dan Burd, SD (2012). Systems Analysis and Design in a Changing World. Cengage Learning. USA.
Subhan, M (2012). Analisa Perancangan Sistem. Jakarta. Lentera Ilmu Cendikia.

Tafiq, R. Muttaqijn, MI. Mukhofa, MI dan Effendi, Y (2020). Sistem Informasi Manajemen. Edisi 2. Graha Ilmu. Yogyakarta.

Taufiq, R. (2018) "Pengantar Sistem Informasi". Jakarta. Mitra Wacana Media.

Taufiq, R., Sulkhan., Yulianti dan Saifudin, A (2020). Analisis dan Desain Sistem Pendukung Keputusan Penilaian Kinerja Pegawai dengan Metode Analytical Hierarchy Process (AHP). Jurnal Informatika Universitas Pamulang. Vol. 5, No. 3. September 2020 (307-314).

Undang-Undang No. 13 Tahun 2003. Tentang Ketenagakerjaan 